\title{
A herança africana e a construção do Estado brasileiro
}

\section{African heritage and the construction of the brazilian State}

\author{
Paulo Roberto de Oliveira ${ }^{a}$ \\ (D) https://orcid.org/0000-0001-9198-0718
}

\begin{abstract}
Resumo: Este artigo tem como objetivo compreender como, de maneira aparentemente paradoxal no Brasil, com uma sociedade erigida em estreita relação com o Continente Africano, se construiu um Estado que desde suas primeiras décadas de existência mostrou-se hostil aos africanos e a seus descendentes, promovendo, ao contrário, a continuidade de uma civilização europeia nos trópicos.

Palavras-chave: Brasil. Formação do Estado. Século XIX. Escravidão. Racismo.
\end{abstract}

\begin{abstract}
This article aims to understand how, in an apparently paradoxical way in Brazil, with a society erected in a close relationship with the African Continent, a State that since its first decades of existence has showed itself hostile to africans and their descendants was built, promoting, on the contrary, the continuation of an european civilization in the tropics.
\end{abstract}

Keywords: Brazil. State Formation. 19th Century. Slavery. Racism. 


\section{Introdução}

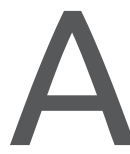

pesar do etnocentrismo evidente, as relações com a África marcaram e marcam o desenvolvimento da sociedade brasileira desde os primeiros tempos coloniais. Milhões de africanos escravizados chegaram até a colônia portuguesa e, a partir de 1822, ao Império brasileiro. Tal presença, além de ser responsável pela construção da riqueza da colônia e do Estado Independente, construiu uma sociedade em que o fenótipo e a influência africana são marcantes. Contudo, desde os primeiros momentos da formação do Estado brasileiro, a elite construtora pautou-se pela construção de uma sociedade e de um Estado que se viam como parte de uma civilização europeia, branca e cristã. Este artigo tem como objetivo compreender esse processo que, apesar de paradoxal, concretizou-se na formação do Estado brasileiro e se tornou a tônica de nossas relações sociais até os dias de hoje.

Com esse intuito, o texto se divide em três partes, além desta introdução. Na primeira parte trata da construção do Brasil no Atlântico Sul, buscando compreender o estabelecimento das relações entre Brasil e África e a herança africana. Na segunda, trata da formação do Estado independente no Brasil e como os seus construtores, brancos, lidaram com a herança africana que, ao mesmo tempo que continuava a construir a riqueza nacional, era alijada da participação nesse processo. Por último, como considerações finais, buscará fazer um balanço da discussão e compreender a persistência da herança africana, apesar da visão europeia que pautou os construtores de nosso Estado independente.

\section{A formação do Brasil no Atlântico Sul}

Foi a expansão comercial europeia que, a partir do século XVI, uniu as duas extremidades do Atlântico Sul em uma mesma lógica e cosmologia, pautada na compreensão de mundo desenvolvida em uma pequena porção do mundo e que, em poucos séculos, dominaria a maior 
parte do globo terrestre. Dentro dos marcos do Antigo Sistema Colonial, após estabelecer relações com as duas costas, os europeus utilizaram o trabalho do africano escravizado para a implementação de um apêndice de sua economia no novo mundo (Novais, 2005; Prado Júnior, 1967). ${ }^{1}$ A região que corresponde à porção oriental da América do Sul foi submetida, transformada em colônia portuguesa, enlaçada pelo sentido da colonização, o qual pressupunha a sua exploração como sua razão de existir. A incorporação de braços africanos se enquadra nesse escopo, justificada por Caio Prado Júnior (1967) pela impossibilidade de utilização da mão de obra indígena. A análise de Fernando Novais (2005), mergulhando nas questões postas por Caio Prado Júnior, buscou compreender o contexto mundial de funcionamento do sistema para, a partir daí, desvelar o funcionamento da colônia portuguesa nas Américas. Nessa perspectiva, para Novais, a incorporação do negro na história brasileira se daria como um negócio da metrópole: uma vez que esse comércio era realizado por portugueses, os lucros aferidos por ele seriam direcionados para a metrópole.

A preocupação de Novais está em entender o funcionamento do Sistema Colonial que, para ele, caracterizava-se principalmente pelas relações entre a metrópole e a colônia - entre Brasil e Portugal. A existência de um grande contingente humano que foi forçado a se deslocar da África para o Brasil já pressuporia uma influência que em muito ultrapassaria os aspectos econômicos (Nascimento, 2019).

Alberto da Costa e Silva, ao tratar da África entre os séculos XVI e XVII, destacou as palavras manilha e libambo, as quais figuram no título de uma de suas obras. A manilha se referia a um bracelete, um ornamento que se fechava em torno do pulso ou do tornozelo em forma de "c", também usado como moeda em algumas regiões. O libambo era uma cadeia de ferro pela qual se jungia uma fila de escravos pelo pescoço. Alberto da Costa e Silva não escolheu essas palavras ao acaso. Ricas em

1 Também houve a ampla utilização do trabalho indígena compulsório. 
significado, elas se referem à África subsaariana que se foi submetida à expansão europeia e transformada em provedora de mão de obra ao novo mundo. Foi a expansão do mercantilismo europeu que as ligou ao continente americano. Contudo, a manilha e o libambo são africanos; fazem parte de uma sociedade que já se desenvolvia e reproduzia relações de troca com moeda, onde havia distinção e hierarquia social e que mantinha relações escravistas (Costa e Silva, 2011).

A África encontrada pelos europeus - entre eles os portugueses como pioneiros na expansão marítima - não foi continente inteiramente submetido pela força (Costa e Silva, 2011). Quando lá chegaram, os habitantes do velho continente não renunciaram à coerção, mas estabeleceram, além disso, relações com os grupos locais que passaram a providenciar a mão de obra cada vez mais demandada à medida que o empreendimento colonial avançava. A escravidão africana era distinta da explorada por europeus e seus descendentes nas Américas. Na África, a escravidão permitia ao escravo preencher diferentes lugares sociais, alguns com prestígio, como a chefia de exércitos. Além disso, se na África a escravidão não se ligava à cor da pele, no novo mundo escravo tornou-se sinônimo de negro e o negro sinônimo de escravizado (Costa e Silva, 2011, p. 849). Foi só após a chegada do colono europeu que o trabalho cativo na África se tornou comercial.

A formação do Brasil também se deu em relação ao continente africano, apesar de isso ser fato pouco enfatizado ao longo de nossa história. O Brasil também se formou no Atlântico Sul. As interpretações do Brasil, em grande medida, foram construídas a partir do exterior, em uma ação marcada pela incompletude (Alencastro, 2010). Por isso, os grandes modelos explicativos do Brasil colonial, como afirma Manolo Florentino (2014) na obra Em costas negras, não dão conta das intensas e complexas relações entre Brasil e África.

Essas relações entre Brasil e África ultrapassavam o entendimento clássico sobre um comércio triangular. Constituíam uma lógica própria que vergava a política portuguesa no Atlântico. As carreiras reforçavam 
o poder de certas aristocracias locais africanas e ampliavam a oferta de escravos nos portos. Além disso, estimulavam o intercâmbio com a África, contribuindo para fixar capitais e equipamentos de navegação nesse setor e para diminuir os custos de transportes no Atlântico Sul (Alencastro, 2010). Grande parte desse negócio de importação de gente se internalizou e passou a ser feito por brasileiros, concentrados principalmente na cidade do Rio de Janeiro, a partir de onde os africanos desterrados eram redistribuídos para outras áreas da colônia portuguesa (Fragoso, 1998).

O comércio do Rio de Janeiro e, consequentemente, do Sudeste fazia-se em grande parte com outras áreas do Império lusitano ao final do século XVIII e início do XIX. No contexto da especialização colonial, o Rio de Janeiro importava a maior parte do que consumia de outras áreas do Império, e não de Portugal. Formou-se, assim, uma economia colonial tardia com uma elite residente no Rio de Janeiro, a qual transformou seu porto no porto da América Latina (Florentino, 2014).

A partir do século XIX, no contexto da Revolução Industrial inglesa e da mudança do tempo da economia mundial, o escravismo do Brasil independente passou a ser questionado pela Inglaterra. Após décadas de conflitos políticos, em 1850 o Brasil aboliu o tráfico escravista e, durante esse mesmo século, a posição dos países ibéricos no continente africano passou a ser questionada e substituída pelas potências da era industrial. Não seria esse, contudo, o fim do escravismo no Brasil, o qual duraria até 1888 , constituindo com "ou sem remorsos, [...] o processo mais longo e mais importante de nossa história” (Costa e Silva, 1994).

Os africanos aqui chegados, frutos da diáspora, da dispersão africana pelo mundo, contribuíram com seus braços, mentes e corações para a construção deste novo Estado, marcado profundamente pela amefricanidade, da qual tratou Lélia Gonzales (1988). Persistiram, como laços insolúveis, as relações entre os dois lados do Atlântico (ver Gilroy, 2012). Por aqui, por anos e anos, por décadas que se prolongavam para aqueles que sustentavam a riqueza sem ter seu quinhão, que prosseguiam sob 
o julgo do cativeiro, deste lado do rio, continuava a se tecer no tear da tragédia as estruturas excludentes que se desdobram até os nossos dias. ${ }^{2}$

\section{A formação do Estado independente, a colonialidade e a negação do outro}

O processo de ruptura do Brasil com a sua condição colonial ocorreu de forma específica dentro do contexto latino-americano. Após séculos de colonização, já havia nas colônias portuguesas nas Américas grupos sociais econômica e politicamente relevantes que se aproveitaram das mudanças no contexto internacional para levar adiante o processo de emancipação. É necessário dar destaque às mudanças políticas europeias, as quais levaram ao avanço napoleônico sobre Portugal e ao deslocamento do centro da monarquia portuguesa para o outro lado do Atlântico, com a consequente abertura dos portos e a elevação do Brasil à condição de Reino Unido a Portugal e Algarves. Tanto quanto isso é necessário ressaltar o papel da Revolução Industrial inglesa, a qual constituiu um novo momento para a economia mundial e ensejou o combate às práticas mercantilistas que sustentavam o monopólio colonial, agora substituídas pelo liberalismo econômico (Hobsbawm, 2010; Novais, 2005). Após a derrota de Napoleão, o rei de Portugal, D. João VI, continuou no Brasil até que, pressionado pela burguesia daquele país promotora da Revolução Liberal do Porto em 1820, foi obrigado a retornar, deixando no comando da ex-colônia seu filho, D. Pedro, o qual, se articulando a camadas da elite brasileira, levou adiante o processo de independência, concretizado simbolicamente em 7 de setembro de 1822 .

A simples ruptura com Portugal não levou de forma automática à formação de um Estado Nacional. Havia diferentes grupos que nos anos

2 Costa e Silva, na apresentação do livro Agudás, de Milton Gurán (2000), usa a expressão “tecer no tear da tragédia” para tratar da construção de um Atlântico de substrato negro pelas relações entre Brasil e África. 
seguintes a 1822 foram cooptados ou submetidos para que a lógica da pátria - país-nação fosse superada. Dentro do panorama colonial, um habitante de Pernambuco tinha como pátria a pernambucana, como país o Brasil e como nação Portugal (Jancsó; Pimenta, 2000). Apesar da construção e dos debates e embates intensos que se seguiram nas próximas décadas, já no momento de concretização da ruptura colonial a manutenção da escravidão serviu como fator agregador de diferentes grupos regionais.

Foi, em grande medida, a elite escravocrata a que garantiu a independência com um discurso que, ao mesmo tempo que defendia a liberdade, agarrava-se às práticas escravocratas que alicerçavam a economia da ex-colônia. Ao analisar a situação da economia brasileira no século XIX, Celso Furtado (1963) destacou o atraso do Brasil no início do século XIX por conta da influência do grupo. Florestan Fernandes (2011) apontou a ação deste na construção da sociedade brasileira e sua obstrução da constituição de uma ordem competitiva, que abriria espaço para a ascensão de novos grupos sociais e econômicos.

A construção do Estado brasileiro se deu em conjunto com a expansão de uma civilização. Ao mesmo tempo que a elite agrária foi chamada para o governo - sobretudo o grupo conhecido como Saquaremas, da região de mesmo nome no Rio de Janeiro - , buscou-se colocar o Brasil como constituinte do rol das nações civilizadas. Em outras palavras, o Estado era construído pela elite agrária escravista cujos membros, ao mesmo tempo que se mantinham como senhores de terras e homens, defendiam a reprodução de uma civilização europeia nestas plagas, com o transplante de um tipo de relações sociais e valores que não se originaram no extra-Europa (Mattos, 2004). Como afirma Mattos (2004), nesse processo deu-se a recunhagem da moeda colonial: na cara dessa moeda, a metrópole foi substituída pelas nações vistas como civilizadas; na outra face a coroa se impôs às regiões, em grande medida pela força, uma vez que nos séculos de submissão a Portugal surgiram na colônia grupos regionais que não se dobraram automaticamente à construção nacional 
e resistiram a esse processo, como foi o caso dos pernambucanos (Melo, 2004). Houve, portanto, a criação de uma classe dirigente juntamente à expansão de uma civilização. 0 processo se resumia em "Civilizar a família patriarcal, construir a classe senhorial e conformar os brasileiros" (Mattos, 2009, p. 36). Mais do que uma questão abstrata, o Estado no Brasil conseguiu burocratizar a sociedade por meio de diferentes ações, como a Guarda Nacional, a qual ficaria a cargo dessa classe dirigente em construção (Uricoechea, 1978). A unidade de pensamento desta foi forjada por um pequeno rol de centros de formação, vedados ao restante da população (Carvalho, 1981). Brasileiros, a partir da construção do Estado, seriam todos aqueles que tendo aderido à causa da independência nas diferentes províncias do antigo Reino do Brasil também contribuíram para a sua expansão "por todo o território que pertencia ao novo corpo político". Os escravizados, que em boa medida lutaram e se encontravam no território, não eram considerados brasileiros (Mattos, 2009, p. 24-25).

Esta construção se torna mais clara se considerarmos alguns aspectos e desdobramentos da dominação colonial. Segundo Santiago Castro-Gómez y Ramón Grosfoguel (2007, p. 13):

El concepto "decolonialidad" [...] resulta útil para trascender la suposición de ciertos discursos académicos y políticos, según la cual, con el fin de las administraciones coloniales y la formación de los Estados-nación en la periferia, vivimos ahora en un mundo descolonizado y poscolonial. ${ }^{3}$

Setembro de 1822 não constitui uma ruptura para a maior parcela dos habitantes desta terra. Ao contrário, as linhas gerais do mundo econômico e social continuaram a se desdobrar e reproduzir-se, em uma sociedade periférica de um sistema que lhes foi imposto. A chegada

3 O conceito de "decolonialidade" [...] é útil para transcender o pressuposto de certos discursos acadêmicos e políticos, segundo os quais, com o fim das administrações coloniais e a formação dos Estados-nação na periferia, passamos a viver em um mundo descolonizado e pós-colonial (tradução do autor). 
europeia às Américas constituiu o desdobramento do mundo europeu para esta região, não só com o desembarque de indivíduos, mas também com o advento de um homem que reproduziu sua sociedade e impôs a sua cosmologia: o homem branco, racista, machista e patriarcal. Não foi, portanto, apenas o desdobramento de um sistema estritamente econômico, mas igualmente de um modo de reprodução da vida pautado por construção social e epistemológica específica (Quijano; Wallerstein, 1992). O racismo resultante foi o alicerce da construção das economias coloniais, seja nas colônias portuguesas com a exploração, sobretudo, do africano escravizado, seja nas colônias espanholas ou de outros Estados europeus com a inferiorização do indígena e a exploração de seu trabalho.

Foi este tipo social que aqui se reproduziu e construiu as nossas instituições que, já é possível notar, possuem a gênese racista e patriarcal. Foram necessárias muita violência física e simbólica, muita imaginação e capacidade de falseamento do processo social, para que esses grupos fossem capazes de construir um país periférico e com a maior população africana fora da África como o europeu. Foram necessários Caxias e Jorge Velho ${ }^{4}$ para que essa construção fosse possível e incorporada de uma forma heroica.

A chegada dos europeus ao solo americano foi fato fundador do Sistema Colonial Moderno; foi aqui que os europeus desenvolveram o padrão de dominação a ser estendido para todo o globo nos séculos posteriores. Uma economia-mundo capitalista não existiria sem as Américas (Quijano; Wallerstein, 1992, p. 583). Deste encontro emergiram a etnicidade e o racismo que pautaram as relações no sistema dentro das nações e entre elas.

4 Luís Alves de Lima e Silva, que foi contemplado com o título de Duque de Caxias pelo Império brasileiro, foi um dos grandes responsáveis pela concretização territorial do Estado no Brasil, agindo contra diferentes focos de levantes regionais e contra ameaças externas, como no caso da Guerra do Paraguai. Domingos Jorge Velho, antes dele, foi responsável pelo ataque ao Quilombo de Palmares, o qual desafiou a política metropolitana portuguesa e, por consequência, o desdobramento e a concretização da sociedade ocidental de origem europeia onde mais tarde seria o Brasil. 
Um exemplo de como o racismo ultrapassou as instituições e se tornou estrutural ${ }^{5}$ está em uma lei de 1831. Dentro do sistema mundial capitalista, o surgimento de novos Estados nacionais dependia do reconhecimento das nações centrais do sistema mundial. A Revolução Industrial inglesa levantou uma barreira às práticas mercantilistas e forçou a adoção do liberalismo; a abertura de mercados servia amplamente aos países que aumentaram a sua produção com a mecanização. Por esse principal motivo, houve uma grande pressão por parte da Inglaterra para que o Brasil deixasse de utilizar a força de trabalho escravizada. Nesse contexto, ao ter sua independência reconhecida pela maior potência mundial, o governo brasileiro comprometeu-se com o fim do tráfico escravista. Obviamente, tal atitude iria de encontro ao interesse dos grandes proprietários de terras brasileiros.

Buscando atenuar esse conflito, o governo brasileiro, em 1831, sancionou a lei que tornava ilegal o tráfico escravista e declarava livre qualquer escravizado que a partir daquela data desembarcasse em solo nacional. Foi uma lei "para inglês ver". A partir do momento em que o Estado brasileiro não se movimentou para que essa lei fosse cumprida, a partir da falta de fiscalização, ela se tornou letra-morta.

Tal debate em torno do tráfico escravista persistiu pelas décadas seguintes, até que, em 1850, ainda por conta da pressão internacional, o tráfico foi extinto por meio da Lei Eusébio de Queirós. Contudo, o escravismo persistiu até 1888. O passo dado com a abolição do tráfico em 1850 foi acompanhado por outro que buscava defender as estruturas de poder concretizadas: foi a Lei de Terras que, ao tornar a terra mercadoria, na verdade fez dela cativa daqueles que podiam adquiri-la (Martins, 1979). Desde então a terra, transformada em mercadoria, seria adquirida por

5 Para Silvio Almeida (2019, p. 50), o racismo é estrutural quando "é uma decorrência da própria estrutura social, ou seja, do modo 'normal' com que se constituem as relações políticas, econômicas, jurídicas e até familiares, não sendo uma patologia social nem um desarranjo institucional". 
aqueles que possuíssem meios para tanto, ou seja, principalmente pelos que já a possuíam.

Ao tratar do lugar reservado ao negro na sociedade brasileira e ao seu extermínio físico e epistemológico, Abdias do Nascimento (2019) tratou desse processo em tom de denúncia, como genocídio. No século XIX, o Instituto Histórico e Geográfico Brasileiro (IHGB) foi uma das instituições que serviram a esse genocídio. O IHGB foi criado em 1838, sob a proteção do imperador D. Pedro II. Segundo Guimarães (1988), no IHGB, Nação, Estado e Coroa apareciam como uma unidade no interior da discussão historiográfica ligada à questão nacional e pretendia construí-la alicerçada na exaltação do Brasil como parte da civilização ocidental cristã, buscando, ao mesmo tempo, sua especificidade neste concerto de nações. Era uma produção amplamente feita e voltada para os grupos dominantes, herdeira da tradição iluminista. A compreensão que ganhava vulto nas páginas da Revista do IHGB era da história como exemplo; nesse intuito se dedicou à criação de biografias de grandes personagens da construção nacional — nenhum deles negro. O negro era tratado como impedimento ao processo civilizador e o indígena constava de maneira idealizada, imbuído dos valores da elite brasileira. Destacavam-se entre os temas principais da revista a problemática indígena, as viagens pelo interior e os debates da história regional. ${ }^{6}$

Em meados do século XIX, com o Estado consolidado, a colonialidade em seus diferentes aspectos se mostrava presente, com uma compreensão de sociedade e de humanidade que excluía os não europeus ou aqueles

6 Ainda sobre o papel do Instituto Histórico e Geográfico Brasileiro como guardião da história oficial, ver Schwarcz (1993). É interessante destacar que mesmo na literatura o indígena foi incorporado como gênesis do Brasil, mesmo na pena dos autores escravocratas, como é o caso de José de Alencar no livro Iracema. Sobre as relações entre literatura e Nação, é interessante a crítica de Kwame Appiah no livro Na casa de meu pai (2010). A existência de uma relação entre literatura e nação, além de esclarecer sobre os elementos considerados na construção desta entidade, por si só desvela a reprodução de um processo que se pretende universal, ou seja, significa a reprodução de uma cosmologia e de uma entre várias possibilidades de organização social. Sobre e a desnaturalização do Estado, ver Clastres (2013). Sobre esse mesmo processo no continente africano, ver Belucci (2010). 
que não possuíam a cor, as crenças ou a cultura europeia. Em $1^{\circ}$ de janeiro de 1852, entrou em vigor o Decreto Imperial de 18 de junho do ano anterior que instituía o registro obrigatório de nascimentos e óbitos. Outro decreto, datado do mesmo dia, previa um recenseamento geral do Império que teria início em julho do mesmo ano. Como destacou Sidney Chalhoub (2012), ao invés do início dos registros o que se assistiu foi a um levante da população contra essas iniciativas. A causa do motim residia no receio de que aquelas iniciativas se destinassem à escravização "da gente de cor" (Chalhoub, 2012, p. 18). As autoridades do Império conseguiram desvelar esse movimento, contudo, fica evidente o peso da escravidão - e do racismo, acrescento - que, segundo Chalhoub (2012, p. 28), tornava precária a experiência da liberdade.

Foram os pretos e os pardos pobres que se revoltaram compreendendo que o Estado Imperial, pouco após o fim do tráfico com a Lei Eusébio de Queirós, pretendia escravizá-los, transformá-los em não pessoas ou, nos parece, concretizar a sua posição como não pessoas, não humanos e não cidadãos. A cor era determinante. No Ocidente, principalmente no caso brasileiro, escravo era igual a negro e a recíproca, na compreensão de mundo colonizado, era verdadeira (Costa e Silva, 2002). Mesmo nos engenhos, houve casos em que a divisão do trabalho respeitava a gradação das cores que separava a população negra segundo o olhar do branco, senhor de terras. As tarefas mais complexas e que sustentavam uma posição mais elevada entre os escravizados eram reservadas aos de pele mais clara (Schwartz, 1988).

O negro no Brasil, mesmo consideradas a diversidade cronológica e geográfica e a amplitude de reações possíveis, quando buscava inserir-se na sociedade brasileira só vislumbrava a possibilidade de sucesso caso se tornasse social e culturalmente branco, abandonando sua herança africana. Só assim seria aceito socialmente e amenizaria o medo e o racismo com que era encarado pelos brancos, mesmo pobres (Mattoso, 2016, p. 242). Abdias do Nascimento destacou essa situação em diferentes momentos de sua obra. No documento 5 do livro 0 quilombismo, tratou de personalidades brasileiras que, ao serem incorporadas socialmente ou 
a buscar ascensão, tornaram-se socialmente brancas (Nascimento, 2019). Essa foi uma das formas como ocorreu no momento de concretização do Estado brasileiro o genocídio do negro brasileiro, por uma ação social, simbólica, física e jurídica que se tornou estrutural em nossa sociedade.

O grande mérito de Abdias do Nascimento, além de sua militância artística e política, foi conseguir conceber, ainda em meados do século passado, quando a discussão acadêmica sobre o Brasil na diáspora africana engatinhava, a questão do negro brasileiro vinculada à questão do negro no Ocidente. ${ }^{7}$ Em grande medida a situação do negro no Brasil, mesmo considerada a sua especificidade, não difere da do negro no Ocidente, em um contexto construído ao longo de séculos e que deixou estruturas que se reproduzem no mundo contemporâneo. É a isso que Grada Kilomba (2019) se refere ao tratar do racismo reiterado e sobre o silenciamento pelo qual a população negra foi submetida no Ocidente. Tal silenciamento e violência epistemológica denunciada por Grada Kilomba talvez expliquem a ausência de Abdias do Nascimento de grande parte da reconhecida bibliografia acadêmica sobre o negro no Brasil. Podem-se apontar imprecisões e não objetividade em parte de seus argumentos. Mas não há uma única análise que passe ilesa, sem crítica, mesmo pelo crivo da academia ocidental e sob o peso esmagador da colonialidade do saber (Castro-Gómez, 2005). ${ }^{8}$

Por último, é necessário destacar que a raça como elemento "científico" e o racismo que deriva dessa leitura de mundo não existiam antes da segunda metade do século XIX, sobretudo no Brasil, onde essas discussões passaram a ser incorporadas e traduzidas para a nossa realidade com

\footnotetext{
Sobre essa compreensão, é interessante registrar a crítica de Appiah (2010, p. 96) segundo a qual a ideia de África, por si só, quando racializada e levada para além dos aspectos geográficos, apresenta-se como fruto do racialismo europeu.

8 A colonialidade do saber diz respeito à maneira como, no Ocidente, foi imposta uma concepção de conhecimento que se torna padrão e se sobrepõe a outras maneiras que passam a ser deslegitimadas. Certamente, para utilizar uma terminologia de Pierre Bourdieu, o campo acadêmico foi construído com esses pilares e reproduz, em grande medida, a legitimação de um saber europeu e a deslegitimação de outras formas de falar sobre o mundo ou concebê-lo.
} 
maior recorrência nas últimas décadas do período imperial (Schwarcz, 1993); apesar disso, como desvela a literatura decolonial, o racismo, mesmo antes de sua sistematização científica, esteve na gênese da cosmovisão formadora das sociedades ocidentais europeizadas. Como afirmou Fernand Braudel (1972), passado e presente iluminam-se mutuamente. Dessa forma, partimos de questões que são nossas quando nos dirigimos ao passado. Enquanto este artigo é escrito, há uma onda de manifestações nos EUA contra o racismo estrutural naquele país. Essas manifestações se tornaram globais e jogaram luzes sobre o racismo estrutural no Brasil e no Ocidente. Se antes do final do século XIX não existia a compreensão de raça do racismo científico, desde o início da era moderna, há a subjugação do outro que se baseia na cor da pele e na ideia de superioridade branca europeia. Não é, por isso tudo, exagero afirmar que as ideias do século XIX deram uma nova roupagem e atualizaram o argumento que sustentava as relações sociais no Ocidente com relação aos não brancos.

\section{Considerações finais: a formação do Estado, a colonialidade e resistência}

Antônio Bispo dos Santos (2019), quilombola autodidata, empreendeu uma boa análise sobre o Brasil e, de certa forma, sobre aspectos ligados à formação do nosso Estado. Em sua obra, os colonizadores são os invasores, aqueles que perpetuam a violência e a exploração. O quilombo é a resistência contracolonizadora. Para ele, o Estado corporifica uma estrutura que perpassa as diferentes temporalidades, que sustenta e dissemina uma cosmovisão europeia que procura se impor às demais interpretações de mundo. Apesar disso há a resistência e, em alguns momentos, o quilombo assalta o Estado (Santos, 2019). ${ }^{9}$ No Brasil, o Estado,

9 É importante destacar que mesmo a centralização política, mesmo aquela que não cria um Estado como o inventado pelos europeus, não pode ser naturalizada. Para isso, é relevante a obra de Pierre Clastres A sociedade contra o Estado (2013). 
formado principalmente sob a gerência e a ação da elite agrária, contou com os braços escravizados para a geração da riqueza que garantiam a criação e sustentavam as suas estruturas, ao mesmo tempo que, de maneira deliberada, criou aparatos que excluíam os negros dos lugares sociais que não o de escravizado, por meio da constituição de instituições que propagavam a colonialidade - em outras palavras, que buscavam legitimar a exclusão e o extermínio epistemológico e físico da população negra; este último, limitado pela necessidade de utilização de seus braços. Achille Mbembe descreveu a plantation como um Estado de exceção. 0 escravizado era concebido como coisa possuída por outra pessoa, "sua existência é a sombra perfeita de uma existência personificada” (Mbembe, 2020, p. 27). A condição de escravo, em suas palavras, resultava em uma tripla perda: perda de um lar, do direito sobre seu corpo e perda do estatuto político. Foi esse possuidor, o homem da boa sociedade, que se colocou como construtor do Estado. A classe dirigente do Estado Brasileiro repousa sobre essa gênese. Destarte, como também colocou Mbembe, o escravo desenvolveu pontos de vista diferentes sobre o tempo, o trabalho e si mesmo (Mbembe, 2020, p. 30). Houve resistência.

Mesmo antes da formação do Estado brasileiro, o quilombo se levantou; diferentes formas de resistência e de reafirmação tiveram lugar, como em Palmares. A formação de quilombos e a constituição destes como espaços de resistência e de reafirmação da existência persistiram, criminalizados, ao longo do século XIX (Moura, 2019). Houve a resistência ao genocídio denunciado por Abdias do Nascimento. Houve Malês, Carrancas. ${ }^{10}$ Ao mesmo tempo, houve quem recorresse à Lei buscando a concretização de um direito negado (Ferreira, 2011). Houve a reprodução das nações africanas em território brasileiro (Costa e Silva, 1994), a formação de famílias que, se atendiam ao clamor dos senhores por pacificação, traziam ao cativo de volta parte de sua humanidade (Motta,

10 Tanto a Revolta dos Malês quanto a de Carrancas, apesar de ocorridas em regiões diferentes, foram importantes demonstrações de resistência dos escravizados frente aos processos colonizadores. 
1999). Nos centros urbanos, houve aqueles que se levantaram contra os seus senhores calcados em uma concepção de direito que não emanava do Estado, mas de sua compreensão de que não poderiam ser vendidos para as fazendas de café, onde a lida era ainda mais extenuante, ou não se curvavam aos castigos considerados injustos por eles (Chalhoub, 1990).

Na segunda metade do século XIX, a obra saquarema estava concluída. Não foi o suficiente para que as contestações cessassem. Naquele momento, o movimento abolicionista questionou a principal base dos construtores do Estado Nacional: a escravatura. Na discussão acadêmica há quem defenda que foi a mudança no sistema capitalista que levou ao final da escravatura no Brasil (Marquese, 2016). Contudo, há que se questionar o timing dessas interpretações. $O$ que garante que as mudanças no sistema capitalista, mesmo que determinantes, teriam alcançado o Brasil em 1888? Parece-nos que, apesar da mudança do cenário internacional, a articulação e a luta abolicionista foram determinantes para os resultados alcançados quando foram alcançados.

Como consequência do movimento abolicionista houve, entre outras, a Lei do Ventre Livre de 1871. Apesar dessa Lei, no que diz respeito ao fato de a libertação dos filhos de cativos trazer uma série de entraves, dentro dela há o dispositivo que de maneira determinante contribuiu para o desfecho alcançado; a partir dela, o cativo teria o direito de comprar a própria liberdade, caso apresentasse ao seu senhor a quantia de dinheiro correspondente ao seu valor de mercado. A partir de então, e isso é de grande relevância, o Estado não mais garantia a posição dos senhores, os quais naquele momento poderiam ver-se obrigados a libertar os seus cativos mesmo contra a sua vontade (Chalhoub, 1990). Aquela década, com outros acontecimentos como o desfecho da Guerra do Paraguai e o Manifesto Republicano, marcou o fim da hegemonia saquarema ${ }^{11}$ e a desagregação que levaria ao fim do período imperial.

11 Os Saquaremas foram o grupo conservador, liderados por grandes cafeicultores do Rio de Janeiro, que sustentou e liderou o pacto político de formação do Estado brasileiro até a década de 1870. Ver Mattos (2004). 
O 13 de maio de 1888, como a culminação de um movimento social que articulou diferentes grupos em torno da causa da abolição (Alonso, 2015) - entre eles os homens livres que também não encontravam papel na estrutura imperial, a chamada arraia miúda (Machado, 2010) —, significou importante etapa na luta da população negra brasileira. Não foi, apesar disso, o fim; não se alcançou a superação do racismo ou a democratização ampla das estruturas de Estado. O golpe republicano significaria uma rearticulação das elites que mais uma vez buscariam a integração a uma ordem internacional como nação civilizada e branca, apostando na miscigenação via trabalhador europeu que, em sua visão, em poucas décadas acabaria com a herança africana.

\section{Referências}

ALENCASTRO, Luiz Felipe de. O trato dos viventes: formação do Brasil no Atlântico Sul, séculos XVI e XVII. São Paulo: Companhia das Letras, 2010.

ALMEIDA, Silvio. Racismo estrutural. São Paulo: Sueli Carneiro; Pólen, 2019.

ALONSO, Angela. Flores, votos e balas: o movimento abolicionista brasileiro (1866-88). São Paulo: Companhia das Letras, 2015.

APPIAH, Kwame. Na casa de meu pai: a África na filosofia da cultura. Tradução: Vera Ribeiro. Rio de Janeiro: Contraponto, 2010. BELLUCCI, Beluce. O Estado na África. Revista Tempo do Mundo, v. 2, n. 3, p. 90-43, 2010.

BRAUDEL, Fernand. História e ciências sociais. Tradução: Carlos Braga e Inácio Canelas. Lisboa: Presença, 1972.

CARVALHO, José Murilo de. A construção da ordem: a elite política imperial. Brasília: Editora UnB, 1981.

CASTRO-GÓMEZ, Santiago. Ciências sociais, violência epistêmica e o problema da 'invenção do outro'. In: LANDER, Edgardo (org.). A colonialidade do saber: eurocentrismo e ciências sociais, perspectivas latino-americanas. Buenos Aires: Clacso, 2005.

CASTRO-GÓMEZ, Santiago; GROSFOGUEL, Ramón. Prólogo. In: CASTRO-GÓMEZ, Santiago; GROSFOGUEL, Ramón. El giro decolonial: reflexiones para una diversidad epistémica más allá del capitalismo global. Bogotá: Siglo del Hombre Editores; Universidad Central, Instituto de Estudios Sociales Contemporáneos y Pontificia Universidad Javeriana, Instituto Pensar, 2007. 
CHALHOUB, Sidney. Visões da liberdade: uma história das últimas décadas da escravidão na corte. São Paulo: Companhia das letras, 1990.

CHALHOUB, Sidney. A força da escravidão: ilegalidade e costume no Brasil oitocentista. São Paulo: Companhia das Letras, 2012.

CLASTRES, Pierre. A sociedade contra o Estado: pesquisas de antropologia política. São Paulo: Cosac \& Naify, 2013.

COSTA E SILVA, Alberto da. Brasil e África no século XIX. Estudos Avançados, São Paulo, v. 8, n. $21,1994$.

COSTA E SILVA, Alberto da. A manilha e o libambo: a África e a escravidão, de 1500 a 1700. Rio de Janeiro: Nova Fronteira, 2002.

COSTA E SILVA, Alberto da. A enxada e a lança: a África antes dos portugueses. Rio de Janeiro: Nova Fronteira, 2011.

FAORO, Raymundo. Os donos do poder: formação do patronato político brasileiro. São Paulo: Globo, 2012.

FERNANDES, Florestan. A revolução burguesa no Brasil: ensaio de interpretação sociológica. São Paulo: Globo, 2011.

FERREIRA, Ligia Maria. Com a palavra Luiz Gama. São Paulo: Imprensa Oficial do Estado de São Paulo, 2011.

FLORENTINO, Manolo. Em costas negras: uma história do tráfico de escravos entre a África e o Rio de Janeiro (séculos XVIII e XIX). São Paulo: Fundação Editora Unesp, 2014.

FRAGOSO, João Luís Ribeiro. Homens de grossa aventura: acumulação e hierarquia na praça mercantil do Rio de Janeiro (1790-1830). Rio de Janeiro: Civilização Brasileira, 1998.

FREYRE, Gilberto. Casa-grande \& senzala: formação da família brasileira sob o regime da economia patriarcal. São Paulo: Global, 2011.

FREYRE, Gilberto. Sobrados e mocambos: decadência do patriarcado rural e desenvolvimento do urbano. São Paulo: Global, 2016.

FURTADO, Celso. Formação econômica do Brasil. Brasília: Editora UnB, 1963.

GILROY, Paul. O Atlântico negro. Tradução: Cid Knipel Moreira. São Paulo: Editora 34, 2012. GONZALEZ, Lélia. A categoria político-cultural da amefricanidade. Tempo Brasileiro, Rio de Janeiro, n. 92/93, p. 69-82, jan./jun. 1988.

GUIMARÃES, Manoel Luís Salgado. Nação e civilização nos trópicos: o Instituto Histórico e Geográfico Brasileiro e o projeto de uma história nacional. Estudos Históricos, Rio de Janeiro, n. 1, p. 5-27, 1988. 
GURÁN, Milton. Agudás: os "brasileiros” do Benim. Rio de Janeiro: Nova Fronteira, 2000. HOBSBAWM, Eric John. A era das revoluções: 1789-1848. Tradução: Maria Tereza Lopes Teixeira e Marcos Penchel. São Paulo: Paz e Terra, 2010.

JANCSÓ, István; PIMENTA, João Paulo G. Peças de um mosaico (ou apontamentos para o estudo da emergência da identidade brasileira). In: MOTTA, Carlos Guilherme. A viagem incompleta: a experiência brasileira (1500-2000). São Paulo: Senac, 2000.

KILOMBA, Grada. Memórias da plantação: episódios de racismo cotidiano. Rio de Janeiro: Cabogó, 2019.

MACHADO, Maria Helena Pereira Toledo. O plano e o pânico: os movimentos sociais na década da abolição. São Paulo: Edusp, 2010.

MARQUESE, Rafael; SALES, Ricardo (org.). Escravidão e capitalismo histórico no século XIX: Cuba, Brasil e Estados Unidos. Rio de Janeiro: Civilização Brasileira, 2016.

MARTINS, José de Souza. O cativeiro da terra. São Paulo: Ciências Humanas, 1979.

MATTOS, Ilmar Rohloff de. O tempo Saquarema: a formação do Estado imperial. São Paulo: Hucitec, 2004.

MATTOS, Ilmar Rohloff de. O gigante e o espelho. In: GRINBERG, Keila; SALLES, Ricardo (org.). O Brasil Imperial (1831-1870). Rio de Janeiro: Civilização Brasileira, 2009. v. 2.

MATTOSO, Kátia M. Queirós. Ser escravo no Brasil: séculos XVI-XIX. Tradução: Sonia Furhmann. Petrópolis: Vozes, 2016.

MBEMBE, Achile. Necropolítica. Biopoder, soberania, estado de exceção, política de morte. São Paulo: N-1 Edições, 2020.

MELO, Evaldo Cabral de. Uma outra independência: o federalismo pernambucano de 1817 a 1824. São Paulo: Editora 34, 2004.

MOTTA, José Flávio. Corpos escravos, vontades livres: posse de cativos e família escrava em Bananal (1801-1829). São Paulo: AnnaBlume, 1999.

MOURA, Clóvis. Sociologia do negro brasileiro. São Paulo: Perspectiva, 2019.

NASCIMENTO, Abdias do. O quilombismo: documentos de uma militância pan-africanista. São Paulo: Perspectiva; Rio de Janeiro: IPEAFRO, 2019.

NOVAIS, Fernando Antonio. Portugal e Brasil na crise do Antigo Sistema Colonial (17771808). São Paulo: Hucitec, 2005.

PRADO JÚNIOR, Caio. História econômica do Brasil. São Paulo: Brasiliense, 1967.

QUIJANO, Aníbal; WALLERSTEIN, Immanuel. La americanidad como concepto, o América en el moderno sistema mundial. RICS 134, dic. 1992. 
SANTOS, Antonio Bispo dos. Colonização, quilombos: modos e significados. Brasília: Associação de Ciências e Saberes para o Etnodesenvolvimento AYO, 2019.

SCHWARCZ, Lilia Mortiz. O espetáculo das raças: cientistas, instituições e questão racial no Brasil 1870-1930. São Paulo: Companhia das Letras, 1993.

SCHWARTZ, Stuart B. Segredos internos: engenhos e escravos na sociedade colonial 1550-1835. Tradução: Laura Teixeira Motta. São Paulo: Companhia das Letras, 1988.

URICOECHEA, Fernando. O minotauro imperial: a burocratização do Estado patrimonial brasileiro no século XIX. Rio de Janeiro: Difel, 1978.

\section{Sobre o autor}

Paulo Roberto de Oliveira - Doutor em História Econômica; docente do Departamento de Ciências Econômicas da Universidade Federal de Ouro Preto (UFOP) e do Programa de Pós-graduação em História da mesma universidade. Tutor do PET - Economia/Conexão de Saberes.

E-mail:prohist@gmail.com.br 